\title{
The Effect of Inspiratory Muscle Training on Respiratory Function in Stroke Patient
}

\begin{abstract}
The purpose of this study was to find out an inspiratory muscles training program's therapeutic effects on stroke patients' respiratory function. For the purpose, this study targeted 20 stroke patients being hospitalized in $\mathrm{K}$ hospital in Daegu, and diveded the patients into the both groups of Inspiratory muscle training(IMT) group and control group, randomization. The 10 patients in the IMT group was applied the inspiratory muscles training. The control group was composed of other 10 patients. IMT group was given a inspiratory muscle training program for 30 minutes per times, 5 times a week for 6 weeks. The investigator measured the patients' respiratory function compared changes in the function and ability before and after the IMT. The results of this study are as follows.

Investigating the inspiratory muscle training group's lung functions, there appeared some significant differences in the tests the $\mathrm{FVC}$ (Forced vital capacity), FEV1(Forced expired volume in one second) before and after the training(p<.05), but the control group had no significant in the same tests before and after(p<.05). The differences in the both groups after depending the inspiratory muscles training were significantly found in the tests of FVC, FEV1, FEV1/FVC(p〈.05). The maximum inspiratory pressure showed some significant differences in the inspiratory muscle training group(p<.05), but didn't show any significant difference in the control group(p>.05). Conclusionally, it will be judged that the inspiratory muscles training program will improve stroke patients' respiratory function, and it is considered that will move up stroke patients' gait and body function.
\end{abstract}

Key words: Inspiratory muscle training; Respiratory function; Breathing exercise; Stroke
Nam Jin Junga, Jung Yeol Jub, Seok Ju Choic, Hyung Soo Shin ${ }^{b}$, Hee Joon Shin ${ }^{\mathrm{b}}$

${ }^{a}$ Kang Hospital, Daegu; ' ${ }^{b}$ yung woon University, Gumi; 'Taegu Science University, Daegu, Korea

Received : 19 November 2014

Revised : 16 December 2014

Accepted : 30 January 2015

Address for correspondence

Hee Joon Shin, PT. Ph.D

Department of Physical Therapy, Kyungwoon University, 30, Sandongmyeon, Gumi, Korea

Tel: 82-54-479-1373

E-mail: Insshj@ikw.ac.kr

\section{INTRODUCTION}

Stroke is a leading cause of disability and death in worldwide(19). The World Health Organization announced that the number of deaths due to stroke accounted for $10 \%$ of all deaths, the number of stroke deaths increased from 650 million in 2015 to 780 million in 2030(24).

There are survivors who surviving stroke patients, with $40 \%$ having moderate functional impairments and $15 \%$ to $30 \%$ severely disabled(7). In addition, Stroke is one of the cerebrovascular diseases remain a major disability for a long period of time, it remain a major disorder to the patients. Therefore, assessment and understanding of disability after stroke should be the first leading to health care(7).
Stroke patients can be seen hypoxia due to the low oxygen saturation, which results shown reduction in cardiopulmonary function. These problems weaken the strength and endurance of the respiratory muscles of stroke patients are occurred muscle fatigue during rehabilitation program or independent exercise is to postpone the functional recovery and return to the activities of daily living(17, 22). Hemiplegia due to stroke may include abnormalities in postural control and motor control. In addition, by reducing the mobility of the respiratory muscles due to damage to the chest wall and abdominal region. These abnormalities affect the respiratory cycle $(5,6)$.

Respiratory weakness of the stroke patients is known to induce muscle fatigue and respiratory failure during functional activities, thereby interfering 
with the ability of daily living, and back muscle strength loss and the degradation of respiratory function reduce phlegm removal capability and cough capacity(26), which in turn causes respiratory tract infection. This raises the mortality of stroke patients, accounting for 20 40\% of the mortality of stroke patients(20, 25, 27).

According to the study by Annoni et al(1990) the decreased lung volume and the increased residual volume are caused by the weakened expiratory and inspiratory muscles, and chronic respiratory dysfunction may raise diaphragm. This is caused by the weakened inspiratory muscle, indicating the significance of inspiratory muscle(15). The results of a study with stroke patients through 8week IMT(Inspiratory Muscle Training) set at 30\% resistance of the maximum inspiration pressure $\left(\mathrm{Pi}_{\text {max }}\right)$ demonstrated the increased inspiratory muscle strength and endurance(5). 6-week IMT with stroke patients improved the contraction of the diaphragm muscle, lung function and the extendibility of thoracic cage(3). Teixeira-Salmela et al(2005). reported that the results of a comparison of 16 stroke patients and 19 healthy adults showed that the inspiration ability of the stroke patients was about $21 \%$ lower than that of healthy adults. Also IMT was effective for improving the weakened inspiration, dyspnea, and apnea at night(25). IMT increases the strength and endurance of inspiratory muscles and the cooperative ability of respiratory system, reduces the respiratory failure and improves the physiological function of subjects(18).

Previously, many studies on the respiration of normal persons in relation with pulmonary disease, spinal cord injury, cerebral palsy and the disease relating to muscles and nervous system have been conducted, yet the studies of the respiratory ability of the stroke patients have seldom been conducted. Thus this study was conducted with the aim to analyze the improvement of the respiratory ability of the stroke patients through 6week IMT.

\section{METHODS}

\section{Subjects}

This study was carried out from August 2013 to October 2013. The experiment subjects were people who has been diagnosed with a stroke, hemiplegic patients, through computed tomography
(CT) and magnetic resonance image(MRI) and were recruited in K rehabilitation center, Deagu, Korea. Since patient safety was the highest priority, every patient was asked to read and sign an informed consent.

\section{Procedure}

The initial assessment of the research subjects was thirty people involved in the study but finally the 20 people; Early discharge of the IMT group four people, one people worse state and early discharge of the control group three people, two people worse state. We used a randomized controlled trial and assigned 10 people to the IMT group and the other 10 to the control group. Both group were given a temporizing Neuro-development treatment(NDT) physical therapy for 30minute per time, 3 times a week, for 6 weeks.

Inclusion criteria of the study are as follow; had no visual field defect and auditory sense; Scored at least 24 on the Mini-Mental State ExaminationKorean(MMSE-K) Independent sitting and gait; had no pulmonary embolus; no neurological, orthopedic problem, or unstable cardiac conditions; had not undergone chest or abdominal sur$\operatorname{gery}(5,21,28)$.

It was measured pulmonary function of the subjects as Spirometer(Spirovit SP-250, Schiller AG, Switzerland), a non-invasive method that can show the physiological function of the lungs, and FVC(Forced Vital Capacity), $\mathrm{FEV}_{1}$ (Forced expiratory volume in one second), $\mathrm{FEV}_{1} / \mathrm{FVC}$, and MV(Minute Volume) was measured to indicate the pulmonary function numerically.

\section{Inspiratory Muscle Training Program}

IMT was performed using a threshold, Respifit S(Inspiratory \& Expiratory Rehabilitation System, Biegler GmbH, Australia). Respifit S has been consisted of a mouthpiece, a re-breathing bag, a display to provide visual feedback. IMT was a measure of the initial maximum inspiratory pressure and then the resistance was conducted in $80 \%$ of the measurements. Using an instrument that represents a visual feedback inspiratory muscle level and see succuss or fail of participants.

Subjects using a nose clip in a comfortable sitting position and then control the breathing through the nose, IMT program was conducted. We have calculated subjects' Pimax(Maximal static inspiratory pressure) and began training with $80 \%$ 
of the maximum resistance. The amount of inhaling and exhaling were displayed and if the amount was over $80 \%$, it was recorded as a success and less than $80 \%$ was recorded as a failure. If subject failed more than three times, we have reset the Pimax and continued the test with new Pimax.

The Training aims to overcome $80 \%$ resistance. The inspiration volume after expiration is displayed. If the dumbbell exceeded $80 \%$ resistance set initially, it was recorded as one success, if not, it was recoded as one failure. In the event of more than 3 failures, the subjects were asked to take a rest and resume the training after the resetting. IMT is set up 10 times in one training set and the two set was carried out, it took a break of $10 \mathrm{sec}^{-}$ onds between each set.

\section{Data analysis}

All analysis were performed using SPSS v.12 for Window and statistical significance was set at $\mathrm{P}$ less than .05. Descriptive statistics was used to evaluate the general characteristics of the subjects. The change in each group's respiratory function between before and after the IMT pro- gram using the paired $t$-test and the change between IMT group and control group using the independent t-test.

\section{RESULTS}

\section{General characteristics of the study subjects}

The General characteristics of the study subjects was tabulated as 〈Table 1〉. All Subjects were recruited 20 people; IMT group was 10 subjects(5 right hemiplegia, 5 left hemiplefia), Control group was 10 subjects(7 right hemiplegia, 3 left hemiplegia).

Investigating the both group's general characteristics, there appear no significant in the tests of Age, on-set, height, weight, MMSE-K(p〉.05).

\section{Comparison of respiratory function}

There was no significant difference between the results of the $\mathrm{F}$-test between the two groups on the FVC, $\left.\mathrm{FEV}_{1}, \mathrm{FEV}_{1} / \mathrm{FVC}, \mathrm{MV}(\mathrm{p}\rangle .05\right)($ Table 2).

Table 1. General characteristics of the study subjects

\begin{tabular}{llccrc}
\multicolumn{1}{c}{ Category } & & IMT group & Control group & t & $\mathrm{p}$ \\
\hline \multirow{2}{*}{ Hemiplegia } & right & 5 & 7 & & \\
& left & 5 & $51.70 \pm 9.74$ & -.151 & .883 \\
\hline Age & $50.90 \pm 11.25$ & $20.40 \pm 14.89$ & .301 & .770 \\
On-set & $22.60 \pm 16.94$ & $169.00 \pm 10.94$ & -.236 & .891 \\
Height & $168.00 \pm 8.97$ & $68.80 \pm 12.00$ & -.628 & .546 \\
Weight & $66.30 \pm 10.29$ & $28.70 \pm 1.16$ & -1.168 & .273 \\
MMSE(score) & $28.20 \pm 1.48$ & & & \\
\hline
\end{tabular}

Table 2. Pulmonary function of the subjects

\begin{tabular}{|c|c|c|c|c|}
\hline Category & IMT group & Control group & $t$ & $\mathrm{p}$ \\
\hline \multicolumn{5}{|l|}{$\mathrm{Pi}_{\max }$} \\
\hline $\mathrm{Pi}_{\max }\left(\mathrm{cmH}_{2} \mathrm{O}\right)$ & $31.20 \pm 12.35$ & $32.20 \pm 6.30$ & -1.140 & .269 \\
\hline Pulmonary function & & & -.609 & .550 \\
\hline $\mathrm{FVC}(\ell)$ & $2.97 \pm .56$ & $3.14 \pm .64$ & -.584 & .565 \\
\hline $\mathrm{FEV}_{1}(l)$ & $2.67 \pm .50$ & $2.79 \pm .48$ & -1.004 & .329 \\
\hline $\mathrm{FEV}_{1} / \mathrm{FVC}(\%)$ & $87.50 \pm 5.40$ & $90.00 \pm 5.74$ & -.506 & .619 \\
\hline $\mathrm{MV}(\ell / \mathrm{min})$ & $23.84 \pm 7.51$ & $25.75 \pm 9.33$ & & \\
\hline
\end{tabular}

$\mathrm{Pi}_{\text {max }}$ : maximal inspiratory pressure sustained for 1 min during incremental test

FVC : forced vital capacity, $\mathrm{FEV}_{1}$ : forced expiratory volume at one second, MV : amount of ventilation 


\section{Comparison of the Pimax}

After inspiratory muscle training for 6 weeks, the $\mathrm{Pi}_{\max }$ showed some significant difference in the IMT group $\left(31.20 \pm 12.35 \mathrm{cmH}_{2} \mathrm{O}\right.$ before and $39.80 \pm 13.00 \mathrm{cmH}_{2} \mathrm{O}$ after $)(\mathrm{p}<.05)$, but did't show any significant difference in the control group $\left(36.20 \pm 6.30 \mathrm{cmH}_{2} \mathrm{O}\right.$ before and $36.40 \pm$ $6.85 \mathrm{cmH}_{2} \mathrm{O}$ after)(p $>$.05)(Table 3). In both group, The differences in the both groups before and after IMT program were significantly found in the test $\mathrm{Pi}_{\text {max }}$ (IMT group; $8.60 \pm 6.06 \mathrm{cmH}_{2} \mathrm{O}$ and control group; .20 $\left.2.27 \mathrm{cmH}_{2} \mathrm{O}\right)(\mathrm{p}<.05)($ Table 4).

\section{Comparison of pulmonary function}

Investigating the IMT group's lung function, there appeared some significant difference in the tests of FVC, $\mathrm{FEV}_{1}$, and MV before and after the IMT program(FVC; $2.97 \pm .56$ before and 3.57 \pm .39 after, $\mathrm{FEV}_{1} ; 2.67 \pm .59$ befoe and $3.09 \pm .25$ after, MV; $23.84 \pm 7.51$ before and $33.10 \pm 10.32$ after)(p<.05), but there was no significant differences in the IMT program influences on the $\mathrm{FEV}_{1} / \mathrm{FVC}$ before and after(FEV $/ \mathrm{FVC} ; 87.50 \pm 5.40$ before and $90.10 \pm 5.55$ after)(p>.05)(Table 5). There was some significant difference between IMT group and control group in FVC, $\mathrm{FEV}_{1}$, $\mathrm{FEV}_{1} / \mathrm{FVC}$ (FVC; IMT group .59 \pm .26 , and control group -.04 $\pm .45, \mathrm{FEV}_{1}$; IMT group $.42 \pm .44$ and control group -.15 $\pm .30, \mathrm{FEV}_{1} / \mathrm{FVC}$; IMT group $2.60 \pm 5.04$ and control group $-6.00 \pm 10.77)(p<.05)$ but the MV showed no significant difference in the both groups(IMT group $9.26 \pm 9.12$ and control group 2.69 \pm 8.67$)(\mathrm{p}\rangle .05)$ (Table 6).

Table 3. Comparison of $\mathrm{Pi}_{\max }$ in IMT training before and after

\begin{tabular}{cccccc}
\hline & Group & before & after & $\mathrm{t}$ & $\mathrm{p}$ \\
\hline \multirow{2}{*}{$\mathrm{Pi}_{\max }\left(\mathrm{CmH}_{2} \mathrm{O}\right)$} & $\mathrm{IMT} \operatorname{group}(\mathrm{n}=10)$ & $31.20 \pm 12.35$ & $39.80 \pm 13.00$ & -4.488 & $.002^{* *}$ \\
& Control group $(\mathrm{n}=10)$ & $36.20 \pm 6.30$ & $36.40 \pm 6.85$ & -.213 & .836 \\
\hline
\end{tabular}

${ }^{*} \mathrm{P}<.01$

$\mathrm{Pi}_{\max }$ : Maximal inspiratory pressure sustained for one minute during incremental test

Table 4. Comparison of $\mathrm{Pi}_{\max }$ between IMT group and Control group

\begin{tabular}{ccccc}
\hline Group & IMT group & Control group & $\mathrm{t}$ & $\mathrm{p}$ \\
\hline $\mathrm{Pi}_{\max }\left(\mathrm{cmH}_{2} \mathrm{O}\right)$ & $8.60 \pm 6.06$ & $.20 \pm 2.97$ & 3.936 & $.001^{* * *}$ \\
\hline${ }^{* * *} \mathrm{P}<.001$ & & & \\
$\mathrm{Pi}_{\text {max }}:$ Maximal inspiratory pressure sustained for one minute during incremental test & &
\end{tabular}

Table 5. Comparison of pulmonary function in IMT training before and after

\begin{tabular}{|c|c|c|c|c|c|}
\hline & Group & before & after & $t$ & $\mathrm{p}$ \\
\hline \multirow{2}{*}{$\mathrm{FVC}(\ell)$} & IMT Group (n=10) & $2.97 \pm .56$ & $3.57 \pm .39$ & -7.188 & $.000^{* * *}$ \\
\hline & Control Group $(n=10)$ & $3.14 \pm .64$ & $3.10 \pm .37$ & .255 & .804 \\
\hline \multirow{2}{*}{ FEV1(l) } & IMT Group (n=10) & $2.67 \pm .50$ & $3.09 \pm .25$ & -3.019 & $.014^{*}$ \\
\hline & Control Group $(n=10)$ & $2.79 \pm .48$ & $2.65 \pm .41$ & 1.556 & .154 \\
\hline \multirow{2}{*}{ FEV $/$ FVC(\%) } & IMT Group(n=10) & $87.50 \pm 5.40$ & $90.10 \pm 5.55$ & -1.632 & .137 \\
\hline & Control Group $(n=10)$ & $90.00 \pm 5.74$ & $84.00 \pm 8.92$ & 1.762 & .112 \\
\hline \multirow{2}{*}{$\mathrm{MV}(\ell / \mathrm{min})$} & IMT Group (n=10) & $23.84 \pm 7.51$ & $33.10 \pm 10.32$ & -3.209 & $.011^{*}$ \\
\hline & Control Group $(n=10)$ & $25.75 \pm 9.33$ & $28.45 \pm 14.80$ & -.981 & .352 \\
\hline
\end{tabular}

${ }^{*} \mathrm{P}<.05,{ }^{* *} \mathrm{P}<.01$

FVC : forced vital capacity, $\mathrm{FEV}_{1}$ : forced expiratory volume at one second, MV : amount of ventilation 
The Effect of Inspiratory Muscle Training on Respiratory function in Stroke Patient

Table 6. Comparison of pulmonary function between IMT group and control group

\begin{tabular}{ccccc}
\hline Group & IMT Group & Control group & $\mathrm{t}$ & $\mathrm{p}$ \\
\hline $\mathrm{FVC}(\ell)$ & $.59 \pm .26$ & $-.04 \pm .45$ & 3.855 & $.001^{* * *}$ \\
$\mathrm{FEV}_{1}(\ell)$ & $.42 \pm .44$ & $-.15 \pm .30$ & 3.371 & $.003^{* *}$ \\
$\mathrm{FEV} / \mathrm{FVC}(\%)$ & $2.60 \pm 5.04$ & $-6.00 \pm 10.77$ & 2.287 & $.035^{*}$ \\
$\mathrm{MV}(\ell / \mathrm{min})$ & $9.26 \pm 9.12$ & $2.69 \pm 8.67$ & 1.649 & .116 \\
\hline
\end{tabular}

${ }^{*} \mathrm{P}<.05,{ }^{* *} \mathrm{P}<.01{ }^{* * *} \mathrm{P}<.001$

FVC : forced vital capacity, $\mathrm{FEV}_{1}$ : forced expiratory volume at one second, MV : amount of ventilation

\section{DISCUSSION}

Stroke may include respiratory failure, which reduces movement and electronic signal of patient's thoracic cage paralyzed side, and directly/indirectly affects cardiopulmonary function(8). Also, hemiparesis by respiratory muscles including diaphragm results insufficient expansion of lung and thoracic and shows contraction phenomenon of chest tissues, and due to fibrosis of pectoral muscles, elasticity of chest reduces(10). Due to these phenomenon, paralyzed side of diaphragm, intercostal muscle, and reduction of abdominal muscle weakens and vital capacity, inspiratory vital capacity, respiratory capacity, inspiratory capacity causes Restrictive Lung Disease(9). Stroke patients with RLD could have risk factors such as Cardiovascular Disease caused by weakened Pimax that diminishes muscular strength of respiration muscle(25).

Kim et al. stated characteristic of patient with RLD are insufficient expansion of lung, and causes FVC and RC to reduce and inspiratory muscle power weakens, then unequal lung expansion causes ventilation-perfusion mismatching. In addition, it affects a lot on respiratory system, change in muscular strength, difficulty of asymmetry posture and postural control, and functional movement disability occurs. This kind of asymmetry posture, weakened muscular strength of respiration muscle, and palsy give change in efficiency of breathing and respiratory mechanism, and to solve this, lung capacity and volume has to be maintained adequately and needs intervention(23).

Griffiths and McConnell conducted 4week respiration training by dividing the subjects into inspiratory muscle training group and expiratory muscle training group. The results showed that there was no significant improvement in the strength of inspiratory and expiratory muscles after IMT, whereas there was significant improvement in the strength of inspiratory and expiratory muscles after expiratory muscle training, indicating the effectiveness of IMT for improving the pulmonary function(12).

Thus based on the results of the previous studies demonstrating the effectiveness of various respiratory training improves the pulmonary function of the stroke patients whose respiratory function was weakened compared to normal persons, the author predicted that the expiratory training strengthening the strength of expiratory muscle of the stroke patients and increasing the lung volume can improve the pulmonary function of the patients. Thus the author analyzed the effect of the IMT equipment on the respiratory function and the maximum inspiration pressure dividing the subjects into expiratory muscle training group and control group.

Jung and Kim(3) performed 6week resistive inspiratory muscle training in the study of the respiratory training of the stroke patients. The results indicated a significant increase in the contraction and thickness of diaphragma at the time of maximum inspiration. 1 second forced expiration and maximum expiration showed a significant increase, yet the ratio of 1 second forced expiration and lung capacity did not show a significant increase. Seo(2) performed 4 week diaphragma expansion and resistance training. The results showed a significant difference in 1 second forced expiration and maximum expiration, but did not show a signifiant difference in the ratio of forced lung capacity of 1second expiration. The results of this study showed the significant difference in the forced lung capacity and 1 second forced expiration in the inspiration muscle 
training group, which was the same as the results from the previous studies. This implies that IMT imposes a load on diaphragma and intercostal muscles, and thus the repeated respiratory training and resistance training improves the strength and endurance of respiratory muscles, resulting in significantly improved pulmonary function.

In recently years, studies on the improvement of respiratory muscles by IMT equipment have been conducted in relation to various diseases(i.e. COPD, spinal cord injury, Parkinson's disease, stroke, heart disease and so on) $(5,11,13)$.

Larson et al(16) said the IMT programs for the chronic obstructive pulmonary diseases using IMT equipment showed a significant increase in the strength and endurance of inspiratory muscles. Sutbeyaz et al(25) said that 6week IMT with acute stroke patients showed a significant improvement in the strength of inspiratory muscles, which helped the recovery of lung volume, lung capacity and respiratory failure. In this study, IMT training with the stroke patients showed a significant increase in the maximum inspiration pressure (from $31.20 \mathrm{cmH}_{2} \mathrm{O}$ to $39.80 \mathrm{cmH}_{2} \mathrm{O}$ ) and a significant increase in the difference between the respiratory training group and control group. This implies that the respiratory training using IMT equipment improves the strength of inspiratory muscles, lung volume and lung capacity.

With regard to the limitations of this study, due to a limited number of subjects and relatively short 6week training period, the author could not generalize the results of this study. Thus there is the necessity of long term study of the stroke patients. In addition, there is the necessity of tracing studies to determine the duration of effect after 6week training and of follow-up studies by tracing the long-term mediating effect of expiratory training with a large number of stroke patients.

\section{CONCLUSION}

In this study, the author intended to determine the effect of respiratory training on the respiratory function using IMT equipment by dividing 20 stroke patients into the respiratory muscle training group(10 stroke patients) and the control group(10 stroke patients). The resulted showed that 6 week IMT results in a significant difference in the respiratory function of the stroke patients before and after IMT.

IMT with the stroke patients showed a significant difference in 1 second forced expiration and forced lung capacity and maximum inspiration.

The results of this study demonstrate the possibility of IMT in improving the respiratory function of the stroke patients, thereby contributing to the rehabilitation of the stroke patients. This implies that it is essential that IMT is included in the treatment plan for the stroke patients along with the physical therapy of neurological.

\section{REFERENCES}

1. Kim YR, Lee SJ, Kim HJ, Lee SB. The Significance of Posture on Assessment of Pulmonary Function after Pulmonary Rehabilitation in Tetraplegia. Annals of Rehabiliation Medicine 2003; 27(4): 513-518

2. Seo KC. The Effect of Pulmonary Function and Respiratory Muscle Activity in the Stroke Patients after Complex Breathing Exercise. Graduate School of Rehabilitation Science Daegu University 2012.

3. Jung JH, Kim NS, Effects of Inspiratory Muscle Training on Diaphragm Thickness, Pulmonary Function, and Chest Expansion in Chronic Stoke Patients. Journal of The Korean Society of Physical Medicine 2013; 8(1): 59-69

4. Annoni JM, Ackermann D, Kesselring J. Respiratory function in chronic hemiplegia. Ins Disabil Stud 1990; 12(2): 78-80

5. Britto NR, Rezende NR, Marinoho KC, Torres J L, Parreira VF, Teixeira-Salmela LF. Inspiratory muscular training in chronic stoke survivors: a randomized controlled tral. Arch Phys Med Rehabil. 2011; 92(2): 194-190.

6. Dickstein R, Shefi S, Marcovitz E, Villa Y. Electromyographic activity of voluntarily activated trunk flexor and extensor muscles in poststroke hemiparetic subjects. Clin Neurophysiol. 2004; 115(4): 790-796.

7. Duncan PW, Horner RD, Reker DM, Samsa GP, Hoenig H, Hamilton B, LaClair BJ, Dudley TK. Adherence to post-acute rehabilitation guidelines is associated with functional recovery in stroke. Stroke. 2002; 33(1):167-177.

8. Ferretti G, Girardis M, Moia C, Antonutto G. Effects of prolonged bed rest on cardiovascular oxygen transport during submaximal exercise in 
humans. Eur J Appl Physiol Occup Physiol. 1998; 78(5):398-402.

9. Frownfelter D, Dean E. Cadriovascular and Pulmonary physical tehrapy: Evidence and Practice. 4th ed. Elsevier Inc. 2006.

10. Fugl-Meyer A. R, Linderholm H, Wilson AF. Restrictive ventilatory dysfunction in stroke: its relation to locomotor function. Scand J Rehabil Med Suppl. 1983; 9:118-124.

11. Geddes EL, Reid WD, Crowe J, O'Brien K, Brooks D. Inspiratory muscle training in adults with chronic obstructive pulmonary disease: a systematic review. Respir Med. 2005 ; 99(11): 1440-1458.

12. Griffiths LA, McConnell AK. The influence of inspiratory and expiratory muscle training upon rowing performance. Eur J Appl Physiol. 2007; 99(5): 457-466.

13. Inzelberg R, Peleg N, Nisipeanu P, Magadle R, Carasso RL, Weiner P. Inspiratory muscle training and the perception of dyspnea in Parkinson's disease. Can J Neurol Sci. 2005; 32(2): 213-217.

14. Kelly JO, Kilbreath SL, Davis GM, Zeman B, Raymond J. Cardiorespiratory fitness and walking ability in subacute stroke patients. Arch Phys Med Rehabil. 2003; 84(12): 1780-1785.

15. Laroche CM, Mier AK, Moxham J, Green M. Diaphragm strength in patients with recent hemidiaphragm paralysis. Thorax. 1988; 43(3): 170-174.

16. Larson JL, Kim MJ, Sharp JT, Larson DA. Inspiratory muscle training with a pressure threshold breathing device in patients with chronic obstructive pulmonary disease. Am Rev Respir Dis. 1988; 138(3): 689-696.

17. Megan K, Kelly, Renee J. Wicker, Thomas J, Barstow, Craig A. Harms Effects of N-acetylcysteine on respiratory muscle fatigue during heavy exercise. Respiratory Physiology \& Neurobiology. 2009; 165: 67-72.

18. Nici L, Donner C, Wouters E, Zuwallack R, Aet al. Committee Ats Ers Pulmonary Rehabilitation Writing. American Thoracic Society/European Respiratory Society statement on pulmonary rehabilitation. Am J Respir Crit Care Med. 2006; 173(12): 1390-1413.

19. Nilanont Y, Nidhinandana S, Suwanwela NC, Hanchaiphiboolkul S, Pimpak T, Tatsanavivat P,
Saposnik G, Poungvarin N, Thai Stroke, Registry. Quality of Acute Ischemic Stroke Care in Thailand: A Prospective Multicenter Countrywide Cohort Study. J Stroke Cerebrovasc Dis. 2013; 1-7.

20. McCool FD, Tzelepis GE. Inspiratory muscle training in the patient with neuromuscular disease. Phys Ther. 1995; 75(11): 1006-1014.

21. Pohl PS, Duncan PW, Perera S, Liu W, Lai SM, Studenski S, Long J. Influence of stroke-related impairments on performance in 6-minute walk test. J Rehabil Res Dev. 2002; 39(4): 439-444.

22. Roffe C, Sills S, Pountain SJ, Allen M. A randomized controlled trial of the effect of fixed-dose routine nocturnal oxygen supplementation on oxygen saturation in patients with acute stroke. $J$ Stroke Cerebrovasc Dis. 2010; 19(1): 29-35.

23. Seo KC, Kim HA, Lim SW. Effects of feedback respiratory exercise and diaphragm respiratory exercise on the pulmonary functions of chronic stroke patients. J Int Acad Phys Ther Res. 2012; 3(2): 413-478.

24. Strong K, Mathers C, Bonita R. Preventing stroke: saving live around the world. Lancet Neurol. 2007; 6: 182-187.

25. Sutbeyaz S T, Koseoglu F, Inan L, Coskun O. Respiratory muscle training improves cardiopulmonary function and exercise tolerance in subjects with subacute stroke: a randomized controlled trial. Clin Rehabil. 2010; 24(3): 240-250.

26. Teixeira-Salmela LF, Parreira VF., Britto RR, Brant TC, Inacio EP, Alcantara TO, Carvalho IF. Respiratory pressures and thoracoabdominal motion in community-dwelling chronic stroke survivors. Arch Phys Med Rehabil. 2005; 86(10): 1974-1978.

27. Van Houtte S, Vanlandewijck Y, Gosselink R. Respiratory muscle training in persons with spinal cord injury: a systematic review. Respir Med. 2006; 100(11): 1886-1895.

28. Verheyden G, Nieuwboer A, Mertin J, Preger R, Kiekens C, De Weerdt W. The Trunk Impairment Scale: a new tool to measure motor impairment of the trunk after stroke. Clin Rehabil. 2004; 18(3): 326-334.

29. World Health Organization. The world health report 2004: changing history. Geneva. World Health Organization. 2004. 